\title{
Trade Effects of Minimum Quality Standards with and without Deterred Entry
}

\author{
Stefan H. Lutz \\ Purdue University and ZEI
}

\begin{abstract}
In a model of vertical product differentiation, duopolistic firms face qualitydependent costs and compete in quality and price in two segmented markets. Minimum quality standards, set uniformly or according to the principle of Mutual Recognition, can be used to increase welfare. The analysis includes entry deterrence by the choice of a particular standard. With identical costs, both industries remain in the market under either regulatory alternative. Mutual Recognition is the optimal policy choice for either region. With signifi cantly different costs, the F ull-Harmonization outcome includes only one firm and leads to a maximal sum of regional welfares. (J E L Classifications: F 12, F21, L13) ४Key Words: product differentiation, oligopoly, trade, quality standards, entry.>
\end{abstract}

\section{Introduction}

With the recent establishment of the European Common M arket, interna-

\footnotetext{
* Correspondence Address: Purdue University, Department of Economics, $1310 \mathrm{~K}$ rannert B uilding, West Lafayette, IN 47907-1310, USA, (E-mail) Lutzs@mgmt.purdue.edu. I would like to thank Massimo Motta, participants at CEPR's European Research Workshop in International Trade held in September 1994 in Rome, Italy, and an anonymous referee for helpful comments and suggestions.
}

(C2000 - Center for International Economics, Sejong Institution. All rights reserved. 
tional coordination of national regulations has gained new importance. This is exemplified by the ongoing efforts to implement the directives on harmonization of standards put forth in the EC Commission's [1985] White paper. Currently, two alternatives to national (destination-oriented) treatment of product standards are prevalent within the EU. Full Harmonization (FH), where uniform standards are set for all member countries, is the goal of the directives contained in the Commission's White paper. In all other cases, as a rule the Country-of-O rigin principle (or principle of Mutual Recognition (M R)) applies. This means that governments set standards for their national industries only while recognizing the adequacy of foreign standards on imported products. ${ }^{1}$ However, support for the harmonization of standards, especially minimum standards concerning product quality, safety, or environmental protection, varies considerably within the EU. In part, this is based on the common belief that these standards, when binding for less advanced national industries but not for more advanced national industries, lead to increased market shares for the latter. Therefore, some of the economically weaker members in the EU fear economic disadvantages from harmonized standards. In contrast to uniform standards, the Country-of-Origin principle allows for national differences in the degree of regulation. In this case, the more advanced national industries might fear to be disadvantaged by higher standards imposed on them by their national governments. On the other hand, all consumers may benefit from increased product qualities caused by standards.

1. Full Harmonization, the main goal until the late 1970s, will be constrained to essential safety and health requirements. In all other cases, as a rule $M$ utual Recognition of national standards applies. As an exception, National Treatment (NT) can be applied in certain cases governed by the EEC Treaty Articles 100 and 36. The differences between the three arrangements are best illustrated using an example. Suppose a F rench and a German manufacturer of household appliances are selling their products in both national markets. Under $\mathrm{FH}$, one standard set by the $\mathrm{EU}$ Council of M inisters applies in both countries. Under M R, German products are governed by German standards even if they are sold in France and French products need only meet $F$ rench standards even if they are sold in Germany (the country-of-origin principle). Under NT, German standards must be met by all products sold in Germany including the French products while French standards must be met by all products sold in France including the German products. 
In this paper I compare the effects of the two alternative standard-setting arrangements on national welfare, industry profits and consumers' welfare using a two-country model of vertical product differentiation. The analysis captures some of the most important aspects of European markets. National industries bear quality-dependend product development costs, choose different quality levels, and compete by setting prices in two segmented national markets. Trade takes place, since both industries are present in both markets. Since increased differentiation in terms of quality decreases competition between rival products, higher quality products will coexist with lower quality products, even if all firms were identical. However, in the presence of technological differences, high-quality products will normally be provided by national industries with low product development costs. Without regulation, equilibrium qualities and prices will not be optimal due to imperfect competition. In response to quality standards, qualities rise, quality differentiation is reduced, and prices adjusted for quality fall. This tends to increase welfare while reducing industry profits. In addition, this analysis explicitly accounts for the possibility that standards are used to restrict market entry. The firm providing the lower product also has lower profits. A quality standard can be set such that this firm's profit opportunities are driven below zero forcing it to exit the market.

The basic features of the model applied here are well-known (M ussa/ Rosen [1978], Gabszewicz/ Thisse [1979], Shaked/Sutton [1982], Ronnen [1991], M otta [1993]). Ronnen uses this framework to demonstrate cases where quality standards improve welfare. He concludes that there exists a binding minimum quality standard such that all consumers are weakly better off, both firms have positive profits, and total welfare is increased. As a result of such a standard, profits of the high-quality provider must fall, whereas profits of the low-quality provider may even rise if the standard is set close to the equilibrium level of low quality without regulation. However, Ronnen starts from the assumption that the chosen order of qualities is already determined, i.e. it is a priori clear which of the firms offers the higher quality. Consequently, Ronnen analyzed firms' quality best responses only in the vicinity of one existing equilibrium. However, with completely endogenous choice of quality, there exist up to two equilibria and each firm's quality best response is discontinuous and contains a high- 
and a low-quality branch, respectively. In this paper, I will demonstrate the derivation of complete quality best responses and the resulting equilibria. ${ }^{2}$ In addition, since there is only one market, the analysis of the case of M utual Recognition is not possible and there is no scope for a welfare analysis in the presence of more than one regulating government. Crampes and $\mathrm{Hol}-$ lander[1995] present a study where quality improvements fall on variable costs. They present results where all consumers lose through the imposition of a standard, contrary to Ronnen. However, this literature is still limited to the analysis of uniform standards in a single market. Similarly, the earlier literature lacks the elements of two-way trade and strategic interaction of governments. ${ }^{3}$ Only recently has the existing analysis been extended to include these features. Boom[1995] introduces $\mathrm{N}$ ational Treatment of standards into a two-country model. Contrary to Ronnen or M otta and Thisse, a relatively high standard imposed in one country can lead to market exit and a reduction of product variety in one country reducing consumers' welfare. But to my knowledge, none of this literature covers M utual Recognition. ${ }^{4}$

The model employed in this paper extends the framework of Shaked/ Sutton and Ronnen for the two-country case. I present a comparison between Full Harmonization and $M$ utual Recognition abstracting from differences in regional demand (market size). ${ }^{5}$ This allows for a better exposition of the effects of these standard arrangements on entry behavior, i.e. a more general exposition of the resulting welfare effects. Standards are initially analyzed

2. These equilibria are in pure strategies. If there are two pure-strategy equilibria, there also exists at least one mixed-strategy equilibrium. However, the analysis of mixedstrategy equilibria is beyond the scope of this work. The emergence of multiple equilibria has also been acknowledged by, e.g., Boom [1995] or Crampes/ Hollander [1995]. The question of selection between two asymmetric equilibria was recently addressed by Motta/Thisse/ Cabrales [1995] who demonstrate how the risk dominance criterion can be utilized for this purpose in models of the type employed here.

3. See, e.g., Leland [1979], Shapiro [1983], B esanko/ Donnenfeld/ White [1988] and Das/ Donnenfeld [1989].

4. In addition, these studies have generally neglected the possibility that a standard may give firms providing high quality the ability to deter entry by potential suppliers of lower qualities.

5. National Treatment is not included in this analysis but has been treated elsewhere. See, e.g., B oom [1995]. 
assuming identical costs. This assumption is relaxed later on.

As in Ronnen, the effects of quality standards on industry competition are primarily driven by their influence on price competition and the qualities produced. Due to the duopoly situation and the nature of price and quality competition, an unregulated equilibrium results in qualities being too low, prices being too high and quality differentiation being too low when compared to a welfare-maximizing solution. When qualities produced become more similar, price competition intensifies. In response to quality standards, qualities rise, quality differentiation is reduced, and prices adjusted for quality fall. In the case of $\mathrm{FH}$, a single standard is binding only for the low-quality provider. High quality rises also because qualities are strategic complements due to the effect of quality differentiation on price competition. Reduced quality differentiation results because increasing quality is increasingly costly. In the two-country case, $\mathrm{FH}$ consists of maximizing the sum of regional welfares subject to a single standard. ${ }^{6}$ Under $M R$, each government maximizes regional welfare subject to its own standard. While $F H$ internalizes effects on welfare of the other region not considered under $M R$, it uses only one regulatory instrument as compared to two under M R. Consequently, we cannot declare one regulatory alternative superior to the other without further analysis.

Assuming that firms have identical cost functions, this analysis shows the following. Introducing MR yields the maximal sum of regional welfares, while introducing either regulatory alternative will increase the sum of regional welfares compared to no regulation. Under $\mathrm{FH}$, i.e. when the objective is to maximize the sum of regional welfares, there exists one local maximum involving only one firm in the market and an increase of regional welfare in both regions compared to the unregulated case. The second and global maximum involves both firms remaining in the market. However, a fully harmonized standard that globally maximizes the sum of regional welfares will lead to a reduction of welfare in the region with the high-quality provider. The low-quality provider earns strictly positive profits, i.e. it is better off than under M R. M R leads to increases of both regional welfares com-

6. M aximizing the sum of regional welfares can be seen as the outcome of N ash-Bargaining between both governments. 
pared to both the case without regulation and the Full-H armonization case (global maximum).

Compared to cases with identical costs, as costs of the low-quality provider increase, the sum of regional welfares under $\mathrm{MR}$ and under $\mathrm{FH}$ (with both firms in the market) decreases, while the sum of regional welfares with only the high-quality provider in the market stays constant. The same holds for the regional welfare of the region with the low-quality provider. With a high enough cost differential, $\mathrm{FH}$ with only one firm in the market will lead to the highest sum of regional welfares. In this case maximizing welfare through a uniform standard involves giving up the viability of the low-quality provider. But this is now also in the interest of the region that loses its industry!

The remainder of the paper is organized as follows. Section II presents the model and market equilibria without minimum quality standards. Market equilibria with minimum quality standards are derived in Section III. A summary and main conclusions are presented in Section IV.

\section{The Model in the Absence of Standards}

\section{A. Basics}

In this section I develop a two-market, partial-equilibrium model of vertical product differentiation. The model describes a two-stage game with firms interacting simultaneously in both stages. To derive solutions, I will use the concept of subgame-perfect equilibrium, computing the solutions for each stage in reverse order. There are two separate regions, the "domestic region" (D) and the "foreign region" (F). M arkets (and demands) in both regions are segmented but identical. There are two firms, the "domestic firm" ( $d$ ) is located in the domestic region and the "foreign firm" ( $f$ ) is located in the foreign region. If entry takes place, then the two firms produce distinct goods, sold at prices $p_{d}$ and $p_{f}$, respectively. The two products carry a single quality attribute denoted by $s_{d}$ and $s_{f}$, respectively. Either firm faces costs of quality development. There are no unit costs of production. Quality development costs are increasing, convex (quadratic) functions of quality, the exact level of which depending on quality chosen and a quality cost 
parameter $b$. Total costs of firm $i$ are then:

$$
c_{i}=b_{i} s_{i}^{2}
$$

In each market, there is a continuum of consumers distributed uniformly over the interval $[0, t]$ with unit density. Each consumer purchases at most one unit of either firm d's product or firm fs product. The higher consumer $i$ 's income parameter $t_{i}$, the higher is her (his) reservation price. Consumer $i$ 's utility is given by equation (2) if good $\mathrm{j}$ is purchased. Consumers who do not purchase receive zero utility.

$$
u_{t i}=s_{j} t_{i}-p_{j}
$$

Firms $d$ and f play a two-stage game ${ }^{7}$. In the first stage, firms determine qualities to be produced and incur costs $c_{i}(i=d, f)$. In the second stage, firms choose prices simultaneously. Note that both firms choose their respective product quality from the same interval $[0, \infty)$. This also means that both firms' choice whether to be the low-quality or the high-quality provider is now endogenous. The resulting market equilibria will include some consumers in the lower segment of the interval $[0, t]$ not valuing quality enough to even buy from the low-quality provider. ${ }^{8}$ B ecause the markets are segmented and demands are identical across regions, each firm's profits are identical across regions. It follows also that consumer surplus is the same across regions. This greatly simplifies the following analysis and allows for dropping regional indices when deriving the main model components.

\section{B. Price Competition}

To solve the game, consider first the demand faced by the high-quality

7. In this formulation, firm i not entering the market is equivalent to firm i choosing $\mathrm{s}_{\mathrm{i}}=$ 0 . The entry decision by firms is made simultaneously when choosing quality.

8. This guarantees an interior solution of the price game. If the distribution of consumers would not cover the entire interval $[0, t]$, but were instead of the form covering the interval $[t-1, t]$, then this would not necessarily be true. If $t$ were large, the firms would cover the whole market. However, including this case would not change the qualitative results to be obtained. 
and low-quality provider in each market, respectively. Let $\mathrm{h}$ and $\mathrm{o}$ stand for high and low quality, respectively. These demands are then given by:

$$
\begin{gathered}
q_{h}=t-\left(\frac{p_{h}-p_{o}}{s_{h}-s_{o}}\right) \\
q_{o}=\frac{p_{h}-p_{o}}{s_{h}-s_{o}}-\frac{p_{o}}{s_{o}}
\end{gathered}
$$

Let $t_{h}=\left(p_{h}-p_{0}\right) /\left(s_{h}-s_{0}\right)$ and $t_{0}=p_{0} / s_{0}$. Consumers with $t_{i}=p_{0} / s_{0}$ will be indifferent between buying the low-quality product and not buying at all. Consumers with $t_{i}=\left(p_{h}-p_{0}\right) /\left(s_{h}-s_{0}\right)$ will be indifferent between buying either the high-quality or the low-quality product. Consumers with $t>t_{i} \geq t_{h}$ will buy high quality, consumers with $t_{h}>t_{i} \geq t_{0}$ will buy low quality, and consumers with $t_{i}<p_{0} / s_{0}$ will not buy at all.

Let $i=h, 0$; let $j \neq i$. The profit function for firm $i$ is given by $\Pi_{i}=$ $p_{i} q_{i}\left(p_{i}, p_{j}, s_{i}, s_{j}\right)-c_{i}\left(s_{i}\right)$. Taken both qualities as given, the price reaction functions in each market are given as the solutions to the first order conditions. Solving the resulting equations for both prices, equilibrium prices are then given as:

$$
p_{h}=\frac{2 t s_{h}\left(s_{h}-s_{o}\right)}{4 s_{h}-s_{o}}, \quad p_{o}=\frac{t\left(s_{h}-s_{o}\right) s_{o}}{4 s_{h}-s_{o}}
$$

Note that for all $s_{n}>s_{0}, t>t_{h}>t_{0}>0$ will hold, i.e., equation (4) is in fact an unconstrained price equilibrium.

Given the price equilibrium depicted above, demands and thus profits can be expressed in terms of qualities. For positive qualities $s_{i}(i=h, 0)$, these profit functions are:

$$
\begin{aligned}
& \Pi_{h}=2 \frac{4 t^{2} s_{h}{ }^{2}\left(s_{h}-s_{o}\right)}{\left(4 s_{h}-s_{o}\right)^{2}}-b_{h} s_{h}{ }^{2} \\
& \Pi_{o}=2 \frac{t^{2} s_{h}\left(s_{h}-s_{o}\right) s_{o}}{\left(4 s_{h}-s_{o}\right)^{2}}-b_{o} s_{o}{ }^{2}
\end{aligned}
$$

\section{Market Equilibria Without Quality Standards}

To derive the firms' quality best responses, I need to investigate each firm's profit function, given the other firm's quality choice, and taking into 
account the behavior in the price-setting subgame. Since the choice of high or low quality as compared to the competitor is endogenous, a firm's profit function will be a composite function, consisting of a segment where low quality is chosen and another segment where high quality i's chosen. Firm i's profit as a function of own quality, $s_{i}$, is then given by:

$$
\begin{aligned}
\Pi_{i}= & 2 \frac{4 t^{2} s_{i}^{2}\left(s_{i}-s_{j}\right)}{\left(4 s_{i}-s_{j}\right)^{2}}-b_{i} s_{i}^{2} \text { for } s_{i} \geq s_{j} ; \\
& 2 \frac{t^{2} s_{i} s_{j}\left(-s_{i}+s_{j}\right)}{\left(-s_{i}+4 s_{j}\right)^{2}}-b_{i} s_{i}^{2} \text { for } 0<s_{i} \leq s_{j} ; \\
& 0 \text { for } s_{i}=0 \\
& \text { where } i=d, f ; j \neq i .
\end{aligned}
$$

Note that equation (6) reduces to the monopoly profits at $\varsigma_{9}=0$, i.e., when the other firm does not enter the market.

The following are properties of the regional revenue functions which will be used extensively in the rest of this paper. Let $R_{t}$ and $M R_{t}$ denote firm i's revenue and marginal revenue functions, respectively, where $t=h$, o specifies whether firm i provides high or low quality. The other firm's quality is denoted by $\mathrm{s}_{\mathrm{j}}$. These properties are verified in the appendix.

$$
\begin{array}{llrl}
\frac{R_{h}}{s_{i}} \geq 0 & \text { (7a); } & \frac{R_{0}}{s_{i}} \geq 0 \text { for } s_{i} \leq \frac{4 s_{j}}{7} \\
\frac{R_{h}}{s_{j}}<0 & \text { (7c); } & \frac{R_{0}}{s_{j}}>0 \\
\frac{M R_{h}}{s_{i}} \leq 0 & \text { (8a); } & \frac{M R_{0}}{s_{i}} \leq 0 \\
\frac{M R_{h}}{s_{j}}>0 & \text { (8c); } & \frac{M R_{0}}{s_{j}}>0
\end{array}
$$

The economic content of these properties lies in the effects that quality choice has on price competition and marginal costs. I make use of these properties in establishing the shape of the profit function which, in turn, will allow for the derivation of firm i's quality best response. For any strictly positive quality chosen by the competitor, a firm can choose either a higher or a lower level of quality. The closer the two qualities are, however, the more 
are profits curtailed by price competition. If both qualities are identical, price equals marginal cost and profit is negative. This implies that an increase in the competitor's quality increases maximum profit in the lowquality segment while decreasing maximum profit in the high-quality segment. Redefine $\Pi_{h}$ and $\Pi_{o}$ as the expressions in the first and second line of the RHS of equation (6), respectively. Lemma 1 describes the shape of firm i's profit function taking the competitor's quality as given. It also describes the change in local profit maxima when the competitor's quality changes. This is illustrated in Figure 1.

\section{Lemma 1.}

Firm i's profit as a function of own quality $s_{i}$ consists of two strictly concave segments, the low-quality segment $\Pi_{o}$ and the high-quality segment $\Pi_{h}$, connected at $s_{\mathrm{i}}=\mathrm{s}_{\mathrm{j}}$ (where $\mathrm{s}_{\mathrm{j}}$ is the competitor's quality). Each of these segments has a unique local maximum, say $\Pi_{o}^{\max }$ and $\Pi_{h}^{\max }$ for the low and the high-quality segment, respectively. As sj approaches zero, $\Pi_{h}^{\max }-\Pi_{o}^{\max }$ approaches a positive limit. For any $s_{\mathrm{j}}$, an increase in $\mathrm{s}_{\mathrm{j}}$ will decrease $\Pi_{h}^{\max }-\Pi_{o}^{\max }$. There exists a unique switchpoint $s_{j}^{*}=\left(s_{j} \mid \Pi_{h}^{\max }-\Pi_{o}^{\max }=0\right)$. At $s_{j}^{*}$, both local profit maxima are positive.

Figure 1

Profit Functions

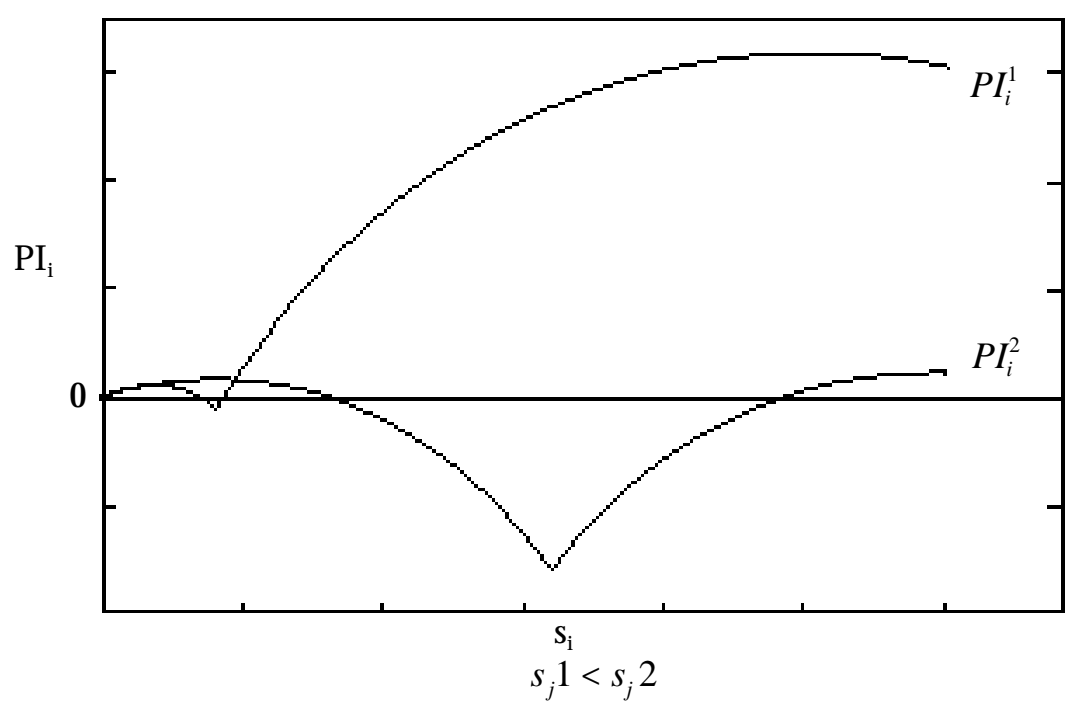


Proof. See the appendix.

Lemma 1 implies that firm i will earn higher profits as the high-quality provider for $s_{\mathrm{j}}$ between zero and the switchpoint $s_{j}^{*}$, while earning higher profits as the low-quality provider for $s_{j}>s_{j}^{*}$.

Hence, firm i's switchpoint is that level of firm j's quality where firm i is indifferent between being the high-quality and the low-quality provider. Profits along firm i's quality best response are decreasing in $\mathrm{s}_{\mathrm{j}}$ for $s_{j}<s_{j}^{*}$, increasing in $\mathrm{s}_{\mathrm{j}}$ for $s_{j}>s_{j}^{*}$, and attain a minimum at the switch point. In the absence of fixed costs, profits along firm i's quality best response are strictly positive for any $\mathrm{s}_{\mathrm{j}}>0$. If $\mathrm{s}_{\mathrm{j}}$ was to change from $s_{j}^{*}-$ to $s_{j}^{*}+$, firm i would switch from being the high-quality provider to being the low-quality provider. Hence, I can derive the shape of firm i's quality best response. This is done in Lemma 2 and illustrated in Figure 2.

\section{Lemma 2.}

a) Firm i's quality best response consists of two segments satisfying the following conditions. For $0 \leq s_{j}<s_{j}^{*}$, firm i provides high quality. For $s_{j}>s_{j}^{*}$, firm i provides low quality. At $s_{1}=s_{j}^{*}$, firm i is indifferent between providing high or low quality. Profits along firm i's quality best response are decreasing in $\mathrm{s}_{\mathrm{j}}$ for $s_{j}<s_{j}^{*}$, increasing in $\mathrm{s}_{\mathrm{j}}$ for $s_{j}>s_{j}^{*}$, and attain a minimum at the switchpoint.

b) Firm i's quality best response is strictly increasing in $\mathrm{s}_{\mathrm{j}}$ for all $s_{j} \neq s_{j}^{*}$.

c) Firm i's quality best response is strictly decreasing in $b_{i}$.

Proof. See the appendix.

The market equilibria in pure strategies without government intervention are simply given by the intersections of the quality best responses. Generally, there will be two pure-strategy equilibria as long as firms are not too different with respect to cost of providing quality. ${ }^{9}$ This is illustrated in Figure 3 for the case of identical firms. ${ }^{10}$ The ratio of high quality to low quality,

9. $N$ ote that in this case, there generally exists at least one non degenerate mixed-strategy equilibrium also.

10. The existence of a unique quality equilibrium due to cost differences can be illustrated using Lemma 2(c) and Figure 3. In Figure 3, an increase in $b_{i}$ would lead to $a$ 
Figure 2

Isoprofit Curves and Quality B est Response

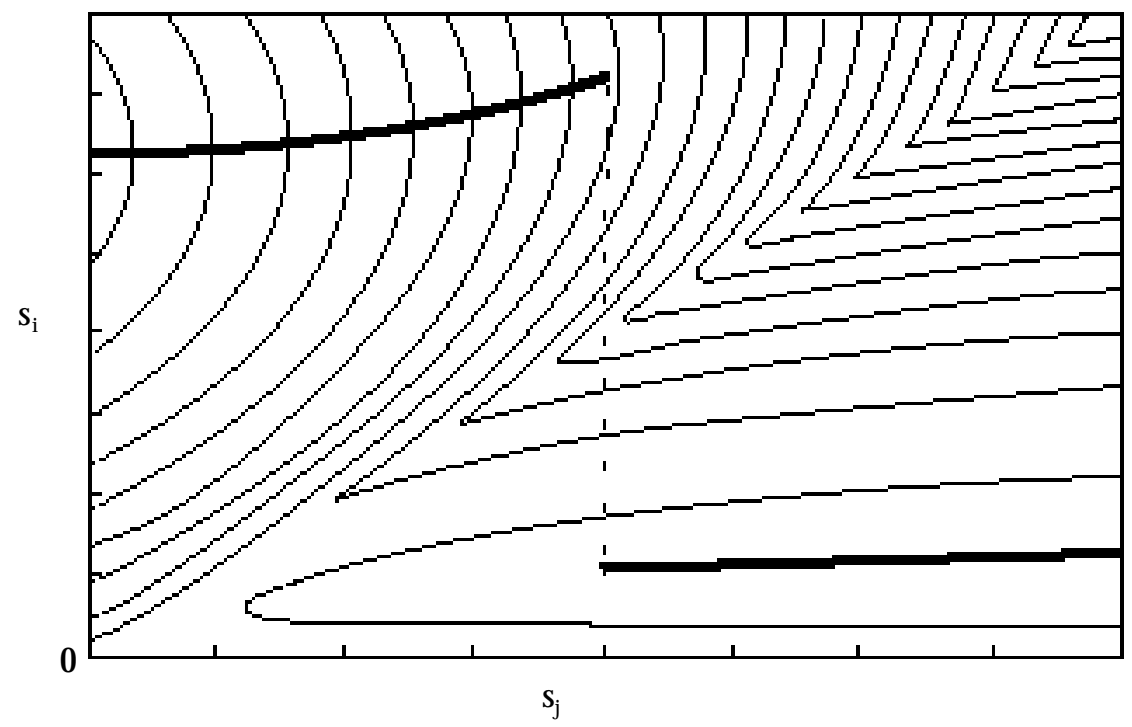

$\mathrm{s}_{\mathrm{h}} / \mathrm{s}_{0}$, is constant with respect to market size t but increases monotonically in $b_{0} / b_{n}$, the ratio of cost parameters. ${ }^{11}$

Consumer surplus for each equilibrium can be expressed in the following way:

$$
C S_{D}=C S_{F}=\frac{t^{2} s_{h}^{2}\left(4 s_{h}+5 s_{0}\right)}{2\left(-4 s_{h}+s_{0}\right)^{2}}
$$

Regional welfare is just the sum of regional consumer surplus and the profit of the firm located in that region. Total welfare is then the sum of the

downward shift in qbri. If $b_{i} / b_{j}$ gets sufficiently large, the intersection of $q_{b r} r_{i}$ and $q_{b r}$ in the northwest corner of Figure 3 vanishes. Only one equilibrium with firm j providing high quality remains.

11. An analytical solution for the equilibrium qualities can be calculated for any given ratio $b_{0} / b_{h}$. This involves solving the first-order conditions in equations (A.3a) and (A.3b) simultaneously. Note that $t / 2 b_{h}$ enters in a multiplicative way and therefore does not affect the calculations.

12. I denote regional welfare of region I as $W_{1}(I=D, F)$ and total welfare as $W=W_{D}+$ $W_{F}$. Alternatively, I can identify a region by the quality level its firm is selling, i.e. $W_{h}$ is the regional welfare of the region with the firm providing high quality. 
Figure 3

Quality Equilibria-Identical Firms

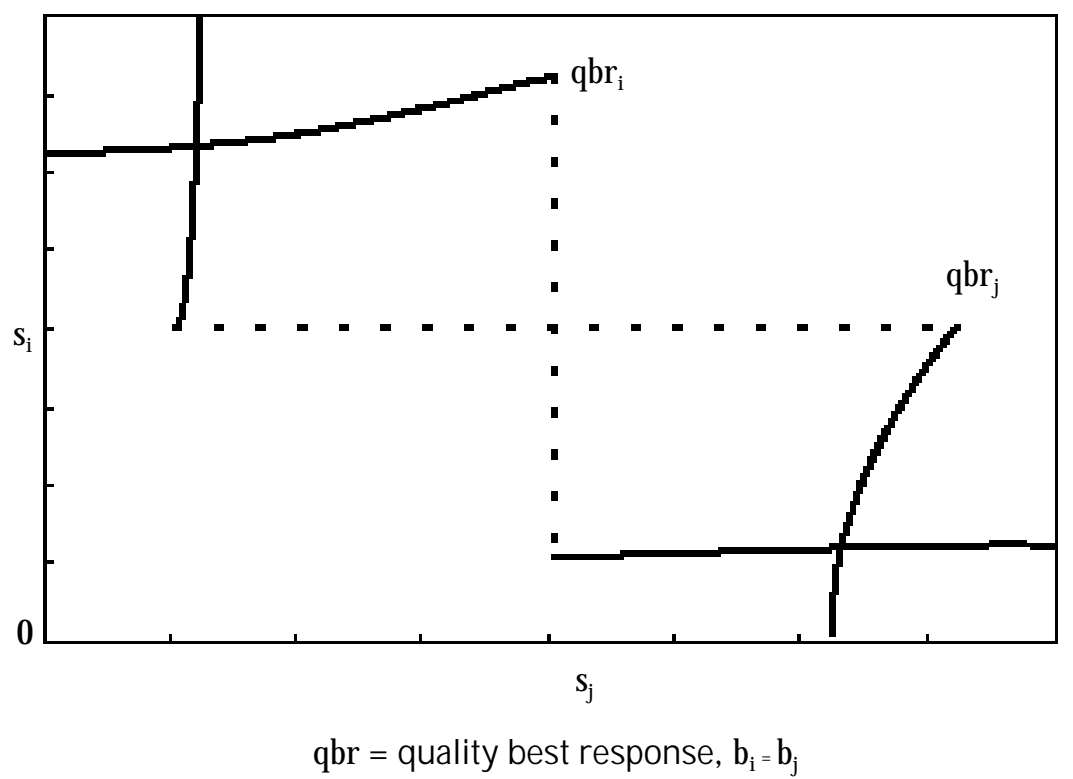

welfare in both regions. ${ }^{12}$ Although welfare can only be calculated after determining which firm provides high quality and which provides low quality, some welfare results can be obtained that hold in either quality equilibrium. The qualities chosen in an unregulated equilibrium will generally not be optimal from the point of view of either government, since each government prefers higher quality levels than those chosen in a market equilibrium. The following properties of consumer surplus in either region will be used to show this. These properties are verified in the appendix. Let $C_{1}(I=$ $D, F)$ denote region I's consumer surplus function. Firms' qualities are denoted by $s_{h}$ and $s_{0}$ for high and low quality, respectively.

$$
\begin{array}{ll}
\frac{C S_{I}}{s_{h}}>0 \text { for } s_{o}<\frac{4 s_{h}}{5} \quad(10 \mathrm{a}) ; & \frac{C S_{I}}{s_{o}}>0 \\
\frac{{ }^{2} C S_{I}}{s_{h}{ }^{2}}=\frac{s_{h}^{2}}{s_{o}{ }^{2}} \frac{{ }^{2} C S_{I}}{s_{o}{ }^{2}}=-\frac{s_{o}}{s_{h}} \frac{{ }^{2} C S_{I}}{s_{o} s_{h}}>0 &
\end{array}
$$

The expression in inequality (10a) is strictly positive for any pair of qualities chosen in a market equilibrium. This is so, since a market equilibrium 
requires the low-quality firm's marginal revenue to be positive, which is only the case if $s_{0}<4 s_{h} / 7$. In both regions, an increase of either quality will lead to increases of consumer surplus at increasing rates. This leads to the result in Lemma 3.

\section{Lemma 3.}

a) Given an unregulated quality equilibrium, regional welfare of both regions can be increased through an appropriate choice of increasing either or both qualities.

b) There exists a single standard that, if imposed in both regions, would increase welfare of both regions.

\section{Proof. See the appendix.}

\section{Corollary 1.}

Starting from an unregulated quality equilibrium, gradually increasing low quality while letting the high-quality provider choose its quality best response will have the following effects on profits: a) the high-quality provider's profits will decrease monotonically; and b) the low-quality provider's profits are concave in low quality, i.e. they increase monotonically up to a single maximum and decrease monotonically thereafter.

Proof: See the appendix.

In the following section I extend the model introduced above to include the interaction of governments that use minimum quality standards as optimizing policy instruments. The two-stage industry game is preceded by a government stage where standards are set that will be constraints for the subsequent industry game. In contrast to the case without regulation, there is now the possibility, that only one firm stays in the market (i.e. offers a quality-level greater than zero).

\section{Market Equilibria With Quality Standards}

\section{A. Full Harmonization}

Under the standard-setting procedure of $\mathrm{FH}$, both governments have agreed to set a single uniform standard that maximizes the sum of regional 
welfares of both regions. This standard will be binding for one of the two firms, namely the low-quality provider. This indicates that the standard-setting problem could be reduced to maximizing the sum of regional welfares with respect to low quality subject to firms' nonnegative-profit conditions and the constraint that the high-quality provider operates on its quality best response. This would lead to a duopoly solution. But since the low-quality provider faces a quality constraint, another condition needs to be satisfied if two firms are to remain in the market. Note that the high-quality provider may be able to deter entry of the low-quality provider by reducing quality differentiation, i.e. setting a quality lower than its (duopoly-) quality best response which, in turn, reduces the low-quality provider's profits to zero. ${ }^{13}$ This is illustrated by the numerical example in Figure 4.

In Figure 4 , a uniform standard of $s_{\min }=s_{0}=0.08$ is set. If high quality is set close to $\operatorname{smin}\left(s_{n}<0.16\right)$, the low-quality provider is not able to make positive profits $\left(\Pi_{o}<0\right)$ and stays out of the market permitting the remaining firm to earn monopoly profits $\Pi_{m}$. But it may also be possible to earn higher duopoly-profits $\Pi_{h}$ by choosing a higher quality. Generally, the high-quality provider will prefer to allow entry at low standards and to deter entry at high standards leading to a quality best response on a uniform standard of the type defined in Proposition 1 below. This is illustrated by the numerical example in Figure 5 where the best response to a standard consists of the segments shown in bold type. ${ }^{14}$ Figure 6 illustrates the derivation of this best response by showing the profits corresponding to the different segments. Consider a uniform standard set such that the low-quality provider's profits were just equal to zero at the high-quality provider's (duopoly-) quality best response. Clearly, the high-quality provider could prevent entry by the low-quality provider by setting its quality marginally lower than its opti-

13. Entry deterrence in the strict sense can occur when one firm is a leader, i.e. it moves first. Under simultaneous entry, a similar case arises then when the equilibrium solution involves one firm staying out. One firm "deters" entry, because the other firm correctly anticipates an equilibrium where it cannot attain positive profits. This scenario implicitly underlies any simultaneous-move market equilibrium involving less than the total number of potential entrants.

14. The case where a uniform standard is binding for the monopolist is not shown in Figures 5 and 6. 
Figure 4

\section{Profit Functions with a Uniform Standard}

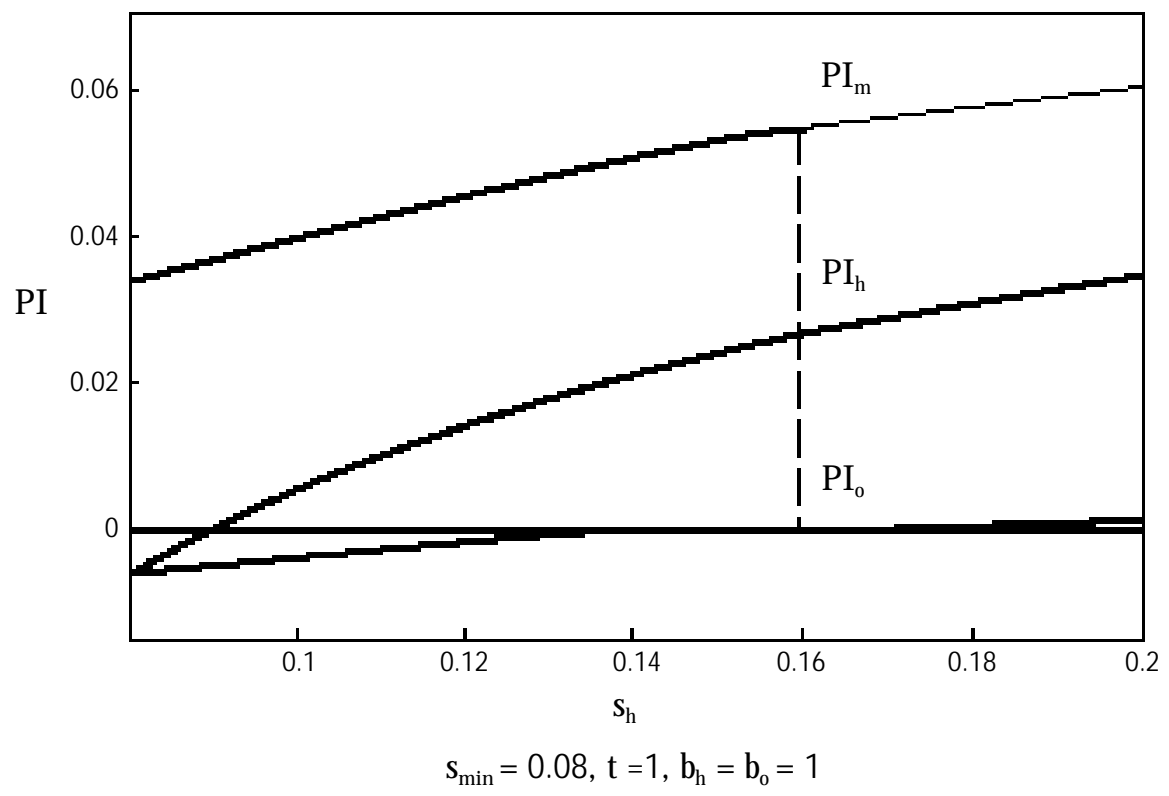

mal duopoly response, thereby increasing its profit. On the other hand, if a standard was set sufficiently high, entry of a low-quality provider would be blockaded, i.e. the remaining firm can set its quality as if it was a monopolist without the threat of entry.

However, deter ring entry in the way described above is only possible, if the low-quality provider cannot profitably respond by setting a quality higher than the firm attempting to deter entry. Hence, quality must be set such that the competing firm can neither earn positive profits as the low-quality provider nor as the high-quality provider. I will refer to the former condition as the zeroprofit condition (zpc) and to the latter as the no-leapfrogging condition ( $\mathrm{nlc}$ ).

Let $\Pi_{i}\left(s_{h}, s_{0}\right)$ [where $i=h, 0$ ] be defined as in equations (5a) and $(5 b)$, respectively. Let $\Pi_{m}\left(s^{\prime \prime}\right)$ be defined as in equation (A.5b) where $s_{m}=s^{\prime \prime}$. Let $q_{b r}\left(s^{\prime}\right)$ be the solution to equation (A.3a) where $s_{j}=s^{\prime}$. Let $s m$ be defined as in equation (A.5C). Denote a minimum quality standard as $S_{\min }$.

Definition. $z p c: \quad s \leq s_{z p c}\left(s^{\prime}\right)=s \mid \Pi_{0}\left(s, s^{\prime}\right)=0$;

nlc: $\quad s \geq s_{n \mid c}$ where $s_{n \mid c}=s \mid \Pi_{n}\left(q b r_{h}(s), s\right)=0$ 
Only if $s_{\min }$ is set such that $s_{z p c}\left(s_{\min }\right) \geq s_{n l c}$, can entry by one firm be prohibited by the other firm's quality choice. Of course, entry will only be deterred, if the resulting monopoly profits are greater than those resulting from accommodating entry. In summary, the best response consists of the four segments: unrestricted high-quality best response, quality such that the other firm's profits are zero, monopoly quality, and quality bound by the standard, respectively. Proposition 1 presents a more formal definition.

\section{Proposition 1.}

The high-quality provider's best response to a uniform quality standard consists of the following four segments:

1) $s_{h}=q b r s_{h}\left(M a x\left(s_{\min }, s_{0}\right)\right)$ for $s_{\min } \leq s_{1}$,

2) $s_{h}=s_{z p c}$ for $s_{1} \leq s_{\min }<s_{2}$,

3) $s_{n}=s_{m}$ for $s_{2} \leq s_{\min }<s_{m}$,

4) $s_{h}=s_{\min }$ for $s_{\min } \geq s_{m}$;

$$
\text { where } \begin{aligned}
s_{1}= & \operatorname{Max}\left[s_{\min } \mid \Pi_{m}\left(s_{z p c}\left(s_{\min }\right)\right)=\Pi_{h}\left(q b r h\left(s_{\min }\right), s_{\min }\right)\right\}, \\
& \left.s_{\min } \mid\left\{s_{n l c}=s_{z p c}\left(s_{\min }\right)\right\}\right], \\
s_{2}= & \left.s_{\min } \mid \Pi_{o}\left(s_{m}, s_{\min }\right)=0\right)
\end{aligned}
$$

Proof. Follows from discussion above.

The remaining condition is therefore that given a minimum quality standard, either nlc is not satisfied or the high-quality provider's duopoly profits must be greater than or equal to monopoly profits at that quality level that would lead to zero-profits by the constrained low-quality provider. Alternatively, the uniform standard could be set so high that only one firm can survive in the market. It follows that there are generally two generic ${ }^{15}$ local maxima, namely one with both firms serving the market and the other with only one firm remaining in the market.

The calculation of the one-firm maximum is straightforward; it is done in the appendix. The calculation of the two-firm equilibrium involves the following steps. Let the high-quality provider's marginal quality best response

15. Actually, there are four local maxima, namely a) firm $d$ offers high quality, b) firm $d$ is a monopolist, firm $f$ offers high quality, and d) firm $f$ is a monopolist 


\section{Figure 5}

High-Quality Best Response with a Uniform Standard

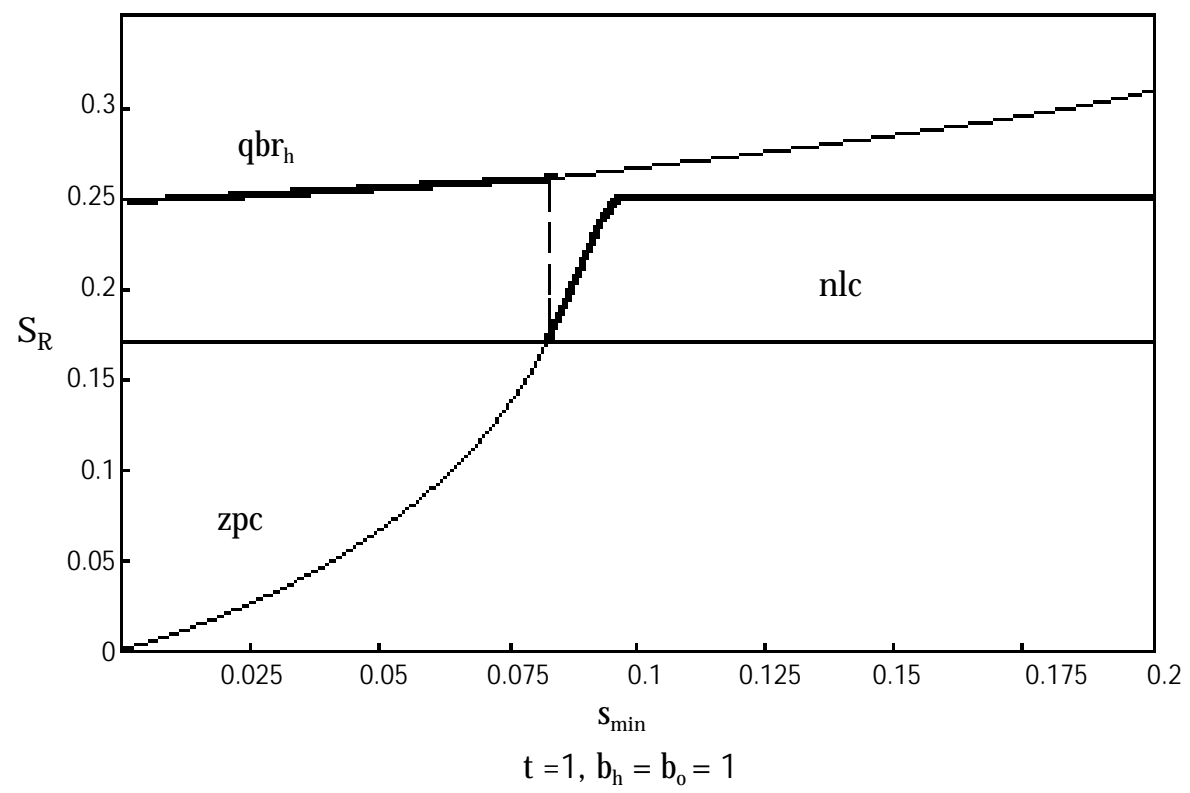

Figure 6

High-Quality B est Response Profits with a Uniform Standard

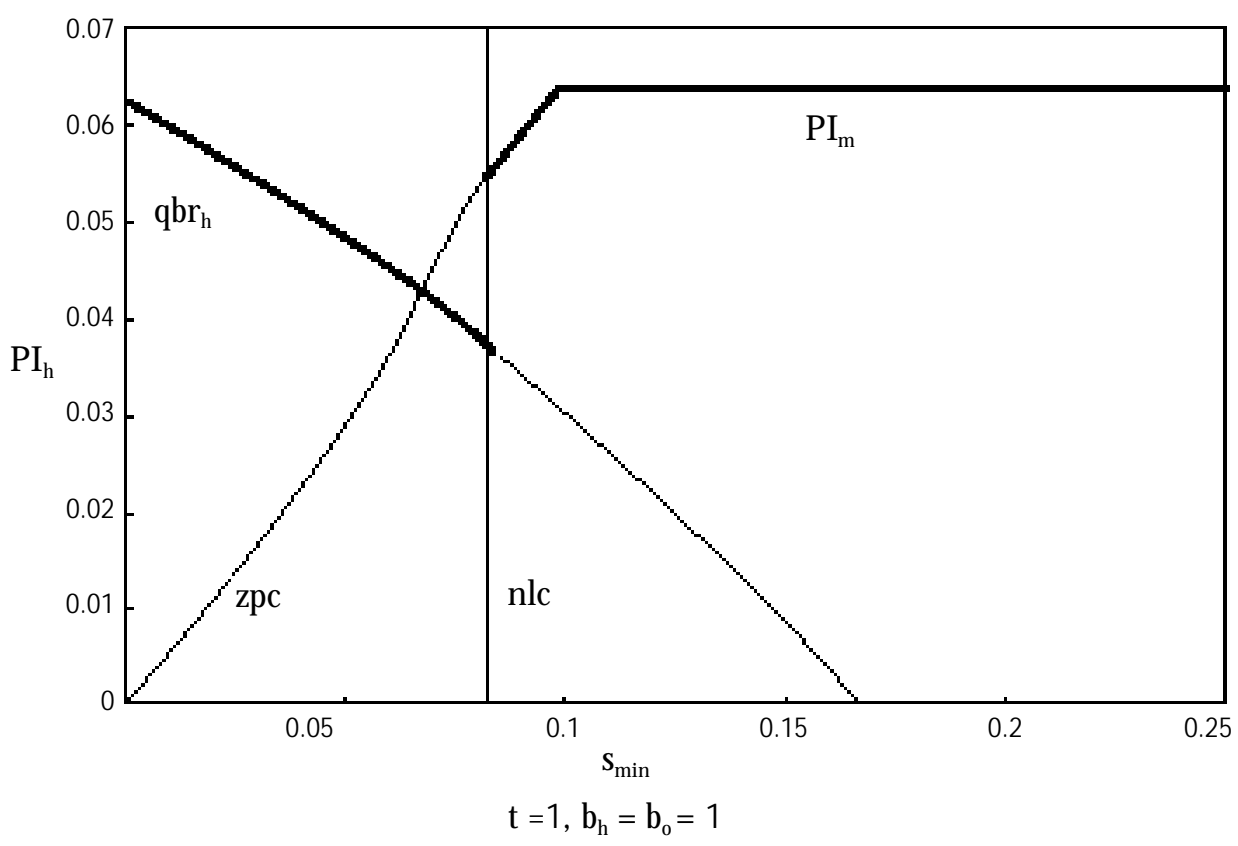


be denoted by $\mathrm{ds}_{n} / \mathrm{ds}_{0}$. Differentiating the objective function with respect to $s_{0}$ yields equation (11).

$$
\frac{d W}{d s_{o}}=\left(M R_{o}-M C_{o}\right)+2 \frac{C S_{I}}{d s_{o}}+\frac{d R_{h}}{d s_{o}}+\frac{d s_{h}}{d s_{o}}\left\{\frac{d R_{o}}{s_{h}}+2 \frac{C S_{I}}{d s_{h}}\right\}
$$

At unconstrained equilibrium qualities, this change is positive since marginal revenue minus marginal cost of quality is zero for both firms, $2 \partial \mathrm{CS}_{\mathrm{l}} / \partial \mathrm{S}_{0}+\partial \mathrm{R}_{\mathrm{h}} / \partial \mathrm{S}_{0}>0$, and the remaining terms on the RHS of equation (11) are all positive. However, as $\mathrm{s}_{0}$ is increased this change diminishes and eventually becomes negative. Differentiating equation (11) another time yields the following expression.

$$
\begin{aligned}
\frac{d^{2} W}{d s_{o}{ }^{2}} & =\left(\frac{d M R_{o}}{d s_{o}}-2 b_{o}\right)+\frac{{ }^{2} R_{h}}{d s_{o}{ }^{2}}+2 \frac{d^{2} C S_{I}}{d s_{o}{ }^{2}}+\frac{d s_{h}}{d s_{o}}\left(\frac{d M R_{h}}{s_{o}}+2 \frac{{ }^{2} C S_{I}}{s_{h} s_{o}}\right) \\
& +\frac{d s_{o}}{s_{o}}\left(\frac{d s_{h}}{d s_{o}}\right)\left(\frac{d R_{o}}{s_{h}}+2 \frac{C S_{I}}{s_{h}}\right)<0
\end{aligned}
$$

It can be shown that the RHS of equation (12) is negative at the choice of $S_{0}$ that sets the RHS of equation (11) equal to zero. ${ }^{16}$ When I simply assume that both firms will stay in the market, this objective function has a single extremum at which it is locally strictly concave. However, at that extremum, profits of the low-quality provider will generally not be nonnegative. ${ }^{17} \mathrm{Con}$ sidering Corollary 1 and the previous discussion, it follows that the welfare maximum with two firms must involve lower qualities than those that could hypothetically be calculated by setting equation (11) equal to zero and those that would lead to zero-profits for the low-quality provider. This also implies that the RHS of equation (11) is positive for any standard leading to positive profits for the low-quality provider. Therefore, the Full-Harmonization solution with both firms in the market can be calculated as described in Proposition 2.

16. This tedious but straightforward calculation yields a result equivalent to equation (A.10) in Lutz ([1993], Appendix A).

17. For identical costs, $\Pi_{0}=-0.00703433 \mathrm{t}^{4} / \mathrm{b}$. It follows immediately that low-quality profits are negative for $b_{0}>b_{h}$. 


\section{Proposition 2.}

The two-firm local maximum of the objective function under $\mathrm{FH}$ can be calculated by choosing a uniform standard $s_{\min }=s_{1}$, i.e.

$$
\left.\left.\operatorname{Max}\left[s_{\min } \mid \Pi_{m}\left(s_{z p c}\left(s_{\min }\right)\right)=\Pi_{h}\left(q b r h\left(s_{\min }\right), s_{\min }\right)\right\}, s_{\min } \mid \$_{n l c}=s_{z p c}\left(s_{\min }\right)\right\}\right] .
$$

Proof. Follows from discussion above.

The examples presented above were calculated assuming identical firms, but all results are valid as long as firms' cost parameters are not too different. The influences of cost differences can be described using Figure 5. As the other firm's cost parameter rises (falls) relative to the high-quality provider's cost parameter, nlc falls (rises) and zpc becomes steeper (flatter). The high-quality provider's ability to deter entry rises (falls).

Consider the case where the other firm's cost parameter rises. Compared to the symmetry-case, the optimal uniform standard maintaining a duopoly must now be lower. The resulting welfare gain is then lower, too. However, the welfare gain from the optimal standard with only one firm in the market remains constant. It follows that setting a standard such that only one firm enters becomes the more attractive the higher the cost difference. ${ }^{18}$

The derivation of standards results for the case of $M R$ is described in the next section.

\section{B. Mutual Recognition}

Under the standard-setting procedure of M R, governments noncooperatively set producer standards for their respective firms and recognize the adequacy of each other's standard. ${ }^{19}$ The two-stage industry game is now preceded by a stage where governments set their respective standards simultaneously. Each government maximizes regional welfare with respect to a minimum quality standard, taking the other government's standard as

18. The discussion of cost differences concentrates on the case where the high-qualityprovider (or monopolist) is the low-cost firm. It is straightforward to show, that this is a necessary condition for optimality of a uniform standard.

19. Recall that each firm's product quality is governed by the regulation of the country of origin, regardless of destination. 
given. Both firms will face binding standards. This means that each government maximizes regional welfare with respect to its own firm's quality subject to nonnegative profits to derive the regional standard best response. It also implies that the high-quality provider has no possibility to preempt entry by the low-quality provider. Differentiating region I's objective function with respect to $s_{i}$ yields equation (13).

$$
\frac{d W_{I}}{d s_{i}}=\left(M R_{i}-M C_{i}\right)+\frac{C S_{I}}{s_{i}}
$$

At the unregulated equilibrium, the RHS of equation (13) is positive for both regions since marginal consumer surplus is positive. ${ }^{20} \mathrm{H}$ owever, as s; is increased this change diminishes and eventually becomes negative. In fact, it can be shown that, under this assumptions, each region's objective function either has a single maximum at which it is locally strictly concave or has a maximum where profits of the local firm just equal zero. ${ }^{21} \mathrm{It}$ follows, that both regional governments have an incentive to set a binding minimum quality for their respective firm. In effect, either firm's quality is now set by its government. This means also, that the governments' standard best responses (to each other's standards) are of the same general shape as firms' quality best responses (illustrated in Figure 1). If costs are not too different, there exist two equilibria. Under large cost differences, only one equilibrium with the low-cost firm providing high quality remains. ${ }^{22}$

I am now in the position to compare results under alternative regulatory ar rangements. These results can be calculated provided the ratio of cost parameters is predetermined..$^{23}$ The next section presents results for identical cost cases.

20. $\mathrm{N}$ ote also that the RHS of equation (13) is positive at $s_{i}=0$. This means that a solution involving only one firm in the market cannot be optimal.

21. For an illustration of this procedure, see equations (A.12a) through (A.12C) in Lutz (1993, Appendix A).

22. Derivation is analogous to that of unregulated equilibria. See Section II.C and F ootnotes 10 and 11 .

23. All calculations for this paper were performed using the "Solve"-routine of M athematica. Solutions are generally valid for any combination of market size $t$ and cost parameters such that $b_{h} / b_{0}$ is constant. 


\section{Regulatory Regimes with Identical Costs}

With identical costs, MR is the optimal policy choice from the point of view of either government. It not only leads to a higher sum of regional welfares than $\mathrm{FH}$ but also makes each country better off compared to either $\mathrm{FH}$ or non-regulation (NR). FH produces a higher sum of regional welfares than NR, but the country which produces high-quality products has a welfare loss. The properties of the M utual Recognition outcome are stated in Proposition 3 below.

\section{Proposition 3.}

With identical costs, the introduction of MR yields maximal welfare for either region. Compared to $N R$, both qualities will rise, profits of either firm will fall, and consumer surplus in either region will rise.

Proof. See Table $1 .{ }^{24}$

Table 1

Outcomes Under Different Regulatory Regimes-Identical Costs

\begin{tabular}{|c|c|c|c|c|}
\hline & $\mathrm{NR}$ & $\mathrm{FH}$ & $\mathrm{FH}_{\mathrm{d}}$ & $\mathrm{MR}$ \\
\hline $\left.\mathrm{S}_{\mathrm{h}}{ }^{*}\right)$ & 0.25331 & 0.26018 & 0.37500 & 0.31625 \\
\hline $\mathrm{S}_{\mathrm{o}}{ }^{*}$ & 0.04823 & 0.08233 & - & 0.10060 \\
\hline$\left.\Pi_{\mathrm{h}}{ }^{* *}\right)$ & 0.04888 & 0.03717 & 0.04688 & 0.02725 \\
\hline$\left.\Pi_{0} * *\right)$ & 0.00305 & 0.00152 & - & 0 \\
\hline $\left.\mathrm{W}_{\mathrm{h}}{ }^{* *}\right)$ & 0.09210 & 0.09068 & 0.09375 & 0.09246 \\
\hline $\left.\mathrm{W}_{\mathrm{o}}{ }^{* *}\right)$ & 0.04627 & 0.05504 & 0.04688 & 0.06521 \\
\hline $\mathrm{W}^{* *)}$ & 0.13837 & 0.14572 & 0.14063 & 0.15767 \\
\hline
\end{tabular}

$\left.b_{0}=b_{h}=b, *\right)$ M ultiply values with $\left.t^{2} / b, * *\right)$ M ultiply values with $t^{4} / b$

$\mathrm{NR}=$ no regulation, $\mathrm{FH}=\mathrm{F}$ ull $\mathrm{H}$ armonization, $\mathrm{FH}_{\mathrm{d}}=\mathrm{FH}$ / only one firm enters, $\mathrm{MR}=\mathrm{M}$ utual

Recognition

Regardless of the standards arrangement chosen, consumer surplus always rises in either region compared to the case without regulation.

24. Solutions are generally valid for any $\left\{t, b_{h}, b_{0}\right\}$ such that $b_{d} b_{h}=1$. 
Under $\mathrm{FH}$, i.e. when the objective is to maximize the sum of regional welfares, there exists one local maximum involving only one firm in the market and an increase of regional welfare in both regions compared to NR. The second and global maximum involves both firms remaining in the market. However, a fully harmonized standard that globally maximizes the sum of regional welfares will lead to a reduction of welfare in the region with the high-quality provider. It is noteworthy, that an agreement on introducing this kind of standard may necessitate a side-payment from the region with the low-quality provider to the region with the high-quality provider unless the viability of the low-quality provider is given up. However, if both firms remain in the market, then the low-quality provider earns strictly positive profits, i.e. it is better off than under M R.

$M R$ leads to increases of both regional welfares compared to both $N R$ and $\mathrm{FH}$ (global maximum). However, the region with the high-quality provider would be better off under $\mathrm{FH}$ with only one firm in the market, even though the sum of regional welfares remains higher under $M R$.

\section{Regulatory Regimes with Different Costs}

Compared to cases with identical costs, as costs of the low-quality provider increase, the sum of regional welfares under $\mathrm{MR}$ and under $\mathrm{FH}$ (with both firms in the market) decreases, while the sum of regional welfares with only the high-quality provider in the market stays constant. This is due to the effects higher costs have on the provision of low quality and on the resulting profits and consumer surplus. Due to increased costs, low quality is reduced and prices must be reduced also. Even though increased quality differentiation allows to ask a higher quality-adjusted price, profits of the low-quality provider are reduced as a result. Since consumers pay a higher quality-adjusted price, consumer surplus goes down. Consequently, if the low-quality provider's costs are very high, i.e. its cost function is convex enough, $\mathrm{FH}$ with only one firm in the market must maximize the sum of regional welfares.

\section{Proposition 4.}

With a high enough cost differential, $\mathrm{FH}$ with only one firm in the market 
Table 2

Outcomes Under Different Regulatory Regimes-Different Costs

\begin{tabular}{|c|c|c|c|c|}
\hline & $\mathrm{NR}$ & $\mathrm{FH}$ & $\mathrm{FH}_{\mathrm{d}}$ & $\mathrm{MR}$ \\
\hline $\left.\mathrm{s}_{\mathrm{h}}{ }^{*}\right)$ & 0.25007 & 0.25029 & 0.37500 & 0.31257 \\
\hline $\left.\mathrm{s}_{\mathrm{o}}{ }^{*}\right)$ & 0.00757 & 0.01497 & - & 0.01523 \\
\hline$\left.\Pi_{\mathrm{h}}{ }^{*}\right)$ & 0.06057 & 0.05861 & 0.04688 & 0.05466 \\
\hline$\left.\Pi_{\mathrm{o}} * *\right)$ & 0.00047 & 0.00002 & - & 0 \\
\hline $\left.\mathrm{W}_{\mathrm{h}}{ }^{* *}\right)$ & 0.09351 & 0.09327 & 0.09375 & 0.09714 \\
\hline $\left.\mathrm{W}_{\mathrm{o}}{ }^{* *}\right)$ & 0.03341 & 0.03467 & 0.04688 & 0.04248 \\
\hline $\left.\mathrm{W}^{* *}\right)$ & 0.12692 & 0.12794 & 0.14063 & 0.13962 \\
\hline
\end{tabular}

$\left.b_{0}=8 b_{h}=8 b, *\right) M$ ultiply values with $\left.t^{2} / b, * *\right) M$ ultiply values with $t^{4} / b$

$\mathrm{NR}=$ no regulation, $\mathrm{FH}=\mathrm{F}$ ull $\mathrm{H}$ armonization, $\mathrm{FH}_{\mathrm{d}}=\mathrm{FH} /$ only one firm enters, $\mathrm{MR}=\mathrm{M}$ utual

Recognition

will lead to the highest sum of regional welfares.

Proof. Follows from the discussion above. This is shown for the case $b_{0}=8$ $b_{h}$ in Table $2 .{ }^{25}$

In this example in Table 2 , any chosen standards alternative will increase consumer surplus in either region compared to NR. Under $F H$, the global maximum involves only one firm in the market and increases regional welfare in both regions compared to NR. N ot surprisingly, in this case maximizing welfare through a uniform standard involves giving up the viability of the low-quality provider. But this is now also in the interest of the region that loses its industry!26 MR leads to increases of both regional welfares compared to NR. Compared to the FH-solution, it leads to a lower sum of regional welfares, higher welfare for the region with the high-quality provider, and lower welfare for the region with the low-quality provider.

\section{Summary and Conclusions}

This paper has analyzed minimum quality standards in a partial-equilibrium model of vertical product differentiation and trade in which duopolistic

25. Solutions are generally valid for any $\left\{t, b_{h}, b_{0}\right\}$ such that $b_{d} / b_{h}=8$.

26. Note that $\mathrm{W}_{0}$ is maximized under $\mathrm{FH}_{\mathrm{d}}$. 
firms face quality-dependent costs and compete in quality and price in two segmented markets. The two alternative standard-setting arrangements of Full Harmonization and M utual Recognition were analyzed and compared. The analysis explicitly accounts for the possibility that standards either create the power to deter entry for some firms or are directly used to restrict market entr y.

In the benchmark case with identical product costs (i.e. identical technologies), M utual Recognition is the optimal policy choice. Full Harmonization becomes a better alternative as differences in product costs become large. In this case, both countries will prefer a uniform minimum standard that permits only the low-cost industry to profitably exist. The country that loses its industry gains nevertheless since it profits from the availability of a superior product. However, under the condition that uniform standards must not induce exit of the low-quality industry, Mutual Recognition is always the preferable regulatory alternative.

Two main conclusions can be drawn from these results. First, the Country-of-O rigin principle should be applied in cases where technological country differences are small or the exit of industries is not a (politically) desirable option. Second, countries should consider accepting uniform standards inducing exit of their national industries from some product markets if these industries face a large technological disadvantage.

\section{References}

Besanko, D., Donnenfeld, S. and L. J. White [1988], "The M ultiproduct Firm, Q uality Choice, and Regulation," Journal of I ndustrial E conomics 36; pp. 411-429.

B oom, A. [1995], "Asymmetric International M inimum Quality Standards and Verticall Differentiation," Journal of Industrial E conomics 43(1); pp. 101-119.

Crampes, C. and A. Hollander [1995], "Duopoly and Quality Standards," European Economic Review 39; pp. 71-82.

Das, S. P. and S. D onnenfeld [1989], "Oligopolistic Competition and International Trade: Quantity and Quality Restrictions," Journal of Internation al E conomics 27(3-4); pp. 299-318. 
Gabszewicz, J. J. and J.-F. Thisse [1979], "Price Competition, Quality and Income Disparities," Journal of E conomic Theory 20; pp. 340-359.

Leland, H. E. [1979], "Quacks, Lemons, and Licensing: A Theory of M inimum Quality Standards," Journal of Political Economy 87; pp. 13281346.

Lutz, S. [1996], "Trade Effects of M inimum Quality Standards With and Without Deterred Entry," CEPR Discussion Paper, No. 1384.

Lutz, S. [1993], "Vertical Product Differentiation, M inimum Quality Standards, and International Trade Policy," Ph.D. Dissertation, Purdue University.

M otta, M . [1993], "Endogenous Quality Choice: Price vs. Quantity Competition," Journal of Industrial E conomics 41; pp. 113-132.

M otta, M ., Thisse, J.-F . and A. Cabrales [1995], "On the Persistence of Leadership or Leapfrogging in International Trade," CEPR Discussion Paper, No. 1106.

M ussa, M . and S. Rosen [1978], "M onopoly and Product Quality," Journal of Economic Theory 18; pp. 301-317.

Ronnen, U. [1991], “M inimum Quality Standards, Fixed Costs, and Competition," Rand Journal of E conomics 22(4); pp. 490-504.

Shaked, A. and J. Sutton [1982], "Relaxing Price Competition Through Product Differentiation," Review of Economic Studies 49; pp. 3-13.

Shapiro, C. [1983], "Premiums for High Quality Products as Returns to Reputations," Quarterly Journal of E conomics 98; pp. 659-679.

Tirole, J. [1988], The Theory of Industrial Organization (MIT Press, Cambridge, MA).

\section{Appendix}

\section{A.1 Properties of the Revenue Functions}

Let $R_{t}$ and $M R_{t}$ denote firm i's regional revenue and marginal revenue functions, respectively, where $t=h$, o specifies whether fir $\mathrm{m}$ i provides high or low quality. The other firm's quality is denoted by s.

$$
\frac{R_{h}}{s_{i}}=\frac{4 t^{2} s_{i}\left(4 s_{i}^{2}-3 s_{i} s_{j}+2 s_{j}^{2}\right)}{\left(4 s_{i}-s_{j}\right)^{3}} \geq 0
$$




$$
\begin{gathered}
\frac{R_{o}}{s_{i}}=\frac{t^{2}\left(\mathrm{Z}_{i}-4 s_{j}\right) s_{j}^{2}}{\left(s_{i}-4 s_{j}\right)^{3}} \geq 0 \text { for } s_{i} \leq \frac{4 s_{j}}{7} \\
\frac{R_{h}}{s_{j}}=\frac{4 t^{2} s_{i}^{2}\left(2 s_{i}+s_{j}\right)}{\left(-4 s_{i}+s_{j}\right)^{3}}<0 \quad \text { (A.1C); } \frac{R_{o}}{s_{j}}=\frac{t^{2} s_{i}^{2}\left(s_{i}+2 s_{j}\right)}{\left(-s_{i}+4 s_{j}\right)^{3}}>0 \\
\frac{M R_{h}}{s_{i}}=\frac{-8 t^{2} s_{j}^{2}\left(5_{i}+s_{j}\right)}{\left(-4 s_{i}+s_{j}\right)^{4}} \leq 0 \quad(\text { A. } 2 \mathrm{a}) ; \quad \frac{M R_{o}}{s_{i}}=\frac{-2 t^{2} s_{j}^{2}\left(7 s_{i}+8 s_{j}\right)}{\left(s_{i}-4 s_{j}\right)^{4}} \leq 0 \\
\frac{M R_{h}}{s_{j}}=\frac{8 t^{2} s_{i} s_{j}\left(5 s_{i}+s_{j}\right)}{\left(-4 s_{i}+s_{j}\right)^{4}}>0 \quad(\text { A. } 2 \mathrm{C}) ; \quad \frac{M R_{o}}{s_{j}}=\frac{2 t^{2} s_{i} s_{j}\left(7 s_{i}+8 s_{j}\right)}{\left(-s_{i}+4 s_{j}\right)^{4}}>0
\end{gathered}
$$

\section{A.2 First-Order Conditions and Slopes of Firms' Quality Best Responses}

The first order conditions for the high and low quality branches of firms' quality best responses are given as:

$$
\begin{aligned}
& \left(2 s_{i}\left(16 t^{2} s_{i}^{2}-64 b_{i} s_{i}^{3}-12 t^{2} s_{i} s_{j}+48 b_{i} s_{i}^{2} s_{j}+8 t^{2} s_{j}^{2}-12 b_{i} s_{i} s_{j}^{2}+b_{i} s_{j}^{3}\right)\right) / \\
& \left(4 s_{i}-s_{j}\right)^{3}=0 \\
& \left(2\left(b_{i} s_{i}^{4}-12 b_{i} s_{i}^{3} s_{j}-7 t^{2} s_{i} s_{j}^{2}+48 b_{i} s_{i}^{2} s_{j}^{2}+4 t^{2} s_{j}^{3}-64 b_{i} s_{i} s_{j}^{3}\right)\right) / \\
& \left(4 s_{j}-s_{i}\right)^{3}=0
\end{aligned}
$$

The slopes of the high and low quality branches of firms' quality best responses are given as:

$$
\begin{gathered}
\left.\frac{d s_{i}}{d s_{j}}\right|_{h}=\left(8 t^{2} s_{i} s_{j}\left(5 s_{i}+s_{j}\right)\right) /\left(256 b_{i} s_{i}^{4}-256 b_{i} s_{i}^{3} s_{j}+40 t^{2} s_{i} s_{j}^{2}+\right. \\
\left.96 b_{i} s_{i}^{2} s_{j}^{2}+8 t^{2} s_{j}^{3}-16 b_{i} s_{i} s_{j}^{3}+b_{i} s_{j}^{4}\right)>0 \\
\left.\frac{d s_{i}}{d s_{j}}\right|_{o}=\left(2 t^{2} s_{i} s_{j}\left(7 s_{i}+8 s_{j}\right)\right) /\left(b_{i} s_{i}^{4}-16 b_{i} s_{i}^{3} s_{j}+14 t^{2} s_{i} s_{j}^{2}+\right. \\
\left.\quad 96 b_{i} s_{i}^{2} s_{j}^{2}+16 t^{2} s_{j}^{3}-256 b_{i} s_{i} s_{j}^{3}+256 b_{i} s_{j}^{4}\right)>0
\end{gathered}
$$

Both slopes are positive, but less than one.

a. Proof of Lemma 1

The concavity properties of the profit function in equation (6) follow from 
concavity of revenues, since costs are convex. Revenues are concave by equations (A.1a), (A.1b), (A.2a) and (A.2b). The first-order conditions for local maxima are shown in equations (A.3a) and (A.3b). As $s_{j}$ approaches zero, $\Pi_{o}^{\max }$ approaches profits at $\mathrm{s}_{\mathrm{i}}=\mathrm{s}_{\mathrm{j}}=0$ equaling 0 , whereas $\Pi_{h}^{\max }$ approaches the monopoly profits. By equations (A.1c) and (A.1d), $\Pi_{h}^{\max }$ decreases and $\Pi_{o}^{\max }$ increases as $\mathrm{s}_{1}$ increases.

\section{b. Proof of Lemma 2}

a) By Lemma 1, for firm i, $\left(\Pi_{h}^{\max }-\Pi_{o}^{\max }\right)>0$ for $s_{j}<s_{j}^{*}$, $\left(\Pi_{o}^{\max }-\Pi_{h}^{\max }\right)>0$ for $s_{j}>s_{j}^{*}$, and $\Pi_{h}^{\max }-\Pi_{o}^{\max }=0$ for $s_{j}=s_{j}^{*}$. By inequalities (A.1C) and (A.1d), $\Pi_{h}^{\max }$ decreases and $\Pi_{o}^{\max }$ increases as $s_{\mathrm{i}}$ increases.

b) At firm i's quality best response, marginal revenue (of quality s) equals marginal cost. An increase in $s_{j}$ increases marginal revenue while leaving marginal cost unchanged. Increasing $s_{i}$ will decrease marginal revenue while increasing marginal cost until marginal revenue equals marginal cost again. See equation (1) and inequalities (A.2a) through (A.2d). The first order conditions for the quality best responses and the resulting slope expressions are shown in equations (A.3) and (A.4).

c) Starting at firm i's quality best response, an increase in bi increases marginal cost while leaving marginal revenue unchanged. Decreasing si will increase marginal revenue while decreasing marginal cost until marginal revenue equals marginal cost again.

\section{c. Proof of Lemma 3}

a) For any pair of qualities chosen in a market equilibrium, marginal profits of both firms are zero, whereas marginal consumer surplus in both regions with respect to both qualities is positive. In addition, an increase in high quality will increase low-quality profit and an increase in low quality will decrease high-quality profit less than consumer surplus increases, i.e. $2 \partial C S_{1} / \partial S_{0}+\partial R_{h} / \partial S_{0}>0$. See equations (A.1C), (A.1d), (A.7a) through (A.7e) and note that by equation (A.1b), $\mathrm{s}_{0}<4 \mathrm{~s}_{h} / 7$ is a necessary condition for lowquality marginal profits to be equal to zero.

b) If a standard were set slightly above low quality in the unregulated 
equilibrium, it would be binding for the low-quality provider, but not for the high-quality provider. Since by equation (A.3a), the high-quality provider's quality best response is increasing in low quality, both qualities will increase. The welfare result follows then from part a).

\section{d. Proof of Corollary 1}

a) Since the high-quality provider increases its quality along its quality best response, this follows directly from Lemma 1 and the accompanying discussion.

b) Let $d s_{h} / d s_{0}$ denote the slope of the high-quality provider's quality best response according to equation (A.4a). At the unregulated equilibrium, the change in the low-quality provider's profits as low quality gradually increases is equal to $\left(d s_{h} / d s_{0}\right)\left(\partial R_{0} / d s_{h}\right)>0$ [by equation (A.1d)], However, as low quality increases, marginal revenue minus marginal cost will become negative and eventually offset the positive effect due to the increase in high quality. It can also be shown that $\left(\partial / \partial s_{0}\right)\left\{M R_{0}-M C_{0}+\left(d s_{h} / d s_{0}\right)\left(\partial R_{0} / d s_{h}\right)\right\}<0$ holds.

\section{A.3 A Single-Product Monopolist}

Equations (A.5a) through (A.5d) show a single-product monopolist's optimal choice of price, profit as a function of quality, optimal choice of quality, and resulting maximal profits, respectively:

$$
\begin{array}{lll}
p_{m}=\frac{t s_{m}}{2} & \text { (A.5a); } & P I_{m}=2 \frac{t^{2} s_{m}}{4}-b_{i} s_{m}^{2} \\
s_{m}=\frac{t^{2}}{4 b_{i}} & \text { (A.5c); } & P I_{m}=\frac{t^{4}}{16 b_{i}}
\end{array}
$$

\section{A.4 Limit of Low-Quality Profits as High Quality Approaches Infinity}

Equation (A.6a) shows the limit of the low-quality provider's profits as high quality approaches infinity, equation (A.6b) shows the level of low quality that maximizes the RHS in equation (A.6a), and equation (A.6C) shows the result of substituting (A.6b) for $s_{0}$ in (A.6a): 


$$
\begin{gathered}
\operatorname{Limit}_{s_{h}} P I_{o}=\frac{t^{2} s_{o}}{8}-b_{o} s_{o}^{2} \quad \text { (A.6a); } \quad s_{o}=\frac{t^{2}}{16 b_{o}} \\
\max _{s_{o}}\left(\text { Limit }_{s_{h}} P I_{o}\right)=\frac{t^{4}}{256 b_{o}}
\end{gathered}
$$

\section{A.5 Properties of the Consumer Surplus Functions}

Let $C S_{I}(I=D, F)$ denote region I's consumer surplus function. Firms' qualities are denoted by sh and so for high and low quality, respectively.

$$
\begin{aligned}
& \frac{C S_{I}}{s_{h}}=\frac{t^{2} s_{h}\left(-8 s_{h}^{2}+6 s_{h} s_{o}+5 s_{o}^{2}\right)}{\left(-4 s_{h}+s_{o}\right)^{3}} \text { (A.7a); } \frac{C S_{I}}{s_{o}}=\frac{t s_{h}^{2}\left(28 s_{h}+5 s_{o}\right)}{2\left(4 s_{h}-s_{o}\right)^{3}}>0 \\
& \frac{{ }^{2} C S_{I}}{s_{h}{ }^{2}}=\frac{t^{2} s_{o}^{2}\left(52 s_{h}+5 s_{o}\right)}{\left(-4 s_{h}+s_{o}\right)^{4}} \quad \text { (A.7C); } \frac{{ }^{2} C S_{I}}{s_{o}^{2}}=\frac{t^{2} s_{h}^{2}\left(5 s_{h}+5 s_{o}\right)}{\left(-4 s_{h}+s_{o}\right)^{4}}>0 \\
& \frac{{ }^{2} C S_{I}}{s_{o} s_{h}}=-\frac{t^{2} s_{h} s_{o}\left(52 s_{h}+5 s_{o}\right)}{\left(-4 s_{h}+s_{o}\right)^{4}}<0
\end{aligned}
$$

\section{A.6 Full Harmonization with Deterred Entry}

Let $\Pi_{m}$ be firm i's profit as a monopolist and $C S_{m}$ be regional consumer surplus when only one product is offered. Equations (A.8a) through (A.8c) show regional consumer surplus, marginal world welfare, and optimal monopoly quality under $\mathrm{FH}$ when the standard is set so high that only one firm prevails. Equation (A.8d) shows regional consumer surplus, monopoly profits and welfare of the region with the monopoly firm when the standard is set according to equation (A.8C).

$$
\begin{gathered}
C S_{m}=\frac{s_{m}}{8} \quad(\mathrm{~A} .8 \mathrm{a}) ; \quad \frac{W}{s_{m}}=\frac{\left(2 C S_{m}+P I_{m}\right)}{s_{m}}=2 \frac{1}{8}+t^{2}-2 b_{i} s_{m} \\
C S_{I}=0.046875 \frac{t^{4}}{b_{i}}, \\
s_{m}=0.375 \frac{t^{2}}{b_{i}} \quad(\mathrm{~A} .8 \mathrm{C})_{m} ;=0.046875 \frac{t^{4}}{b_{i}}, \\
W_{m}=0.09375 \frac{t^{4}}{b_{i}}
\end{gathered}
$$




\section{A.7 Derivation of the No-Leapfrogging Condition}

This is derived by maximizing the high-quality isoprofit curve with respect to low quality subject to profit equaling zero. For any $\left\{t, b_{n}, b_{0}\right\}, I$ have $\mathrm{s}_{\mathrm{n} \mid \mathrm{c}}=\mathrm{t}^{2} /\left(6 \mathrm{~b}_{0}\right)$. 